\title{
THE ORIGIN OF THE PERONEAL COMMUNICATING NERVE IN ADULT MAN
}

DONALD F. HUELKE

Department of Anatomy, University of Michigan Medical School, Ann Arbor, Michigan

BIGHT FIGURES

\section{INTRODUCTION}

The standard textbooks of gross anatomy - Cunningham, Gray, and Morris - agree that the peroneal communicating nerve (N.A.P.-1955) is usually a branch of the lateral sural cutaneous nerve. Recently Williams ('54) reported the peroneal communicating nerve as being a direct branch of the common peroneal nerve in the majority of cases $(93 \%)$. Previously, however, other authors (Kosinski, '26; Bardeen, '06; Mogi, '38; P'an, '39; Catania, '24; Andreassi, '31; and Ssokolow, '33) have provided data which agree with the usual textbook descriptions. It is the purpose of this paper to present further data on the origin of the peroneal communicating nerve in an attempt to reconcile these conflicting reports.

\section{MATERIAL}

Dissections were made on 99 adult cadavers, of which 92 were Caucasians (77 males and 15 females) and 7 were male Negroes. Both lower limbs of each cadaver were used, providing 198 extremities for study. The cadavers used for a previous study (Huelke, '57) were of another sampling.

\section{OBSERVATIONS AND RESULTS}

The sural nerve is formed by the union of the peroneal communicating nerve with the medial sural cutaneous nerve. 
This union was seen on 159 sides ( $80.3 \%$ ). The peroneal communicating nerve was absent on $19.7 \%$ of sides. Of the total number of sural nerves observed (159), the union of the peroneal communicating nerve with the medial sural cutaneous nerve was found in the lower half of the leg in $75 \%$.

The peroneal communicating nerve was combined in some way with the lateral sural cutaneous nerve in $58.5 \%$ of the 159 sides. In $33.3 \%$ the peroneal communicating nerve followed the typical textbook description-being one of the terminals of the lateral sural cutaneous nerve (figs. 1 and 7). At times (13.2\%), the peroneal communicating nerve appeared to be the main stem, giving off cutaneous branches to the posterior aspect of the leg (fig. 4). These may be thought of as lateral sural cutaneous branches, and thus, the lateral sural cutaneous nerve was considered to arise from the peroneal communicating nerve in these cases. This type of peroneal communicating nerve has not been described previously. In $12 \%$ of the 159 sides, the peroneal communicating and lateral sural cutaneous nerves arose by a common trunk (fig. 5). This trunk bifurcated over the lateral head of the gastrocnemius muscle into the peroneal communicating and the lateral sural cutaneous nerves. The peroneal communicating nerve then continued into the distal part of the leg where it joined the medial sural cutaneous nerve to form the sural nerve.

The peroneal communicating nerve arose directly from the common peroneal nerve and separate from the lateral sural cutaneous nerve in $41.5 \%$ of the 159 sides. In $22 \%$ it was the only branch of the common peroneal nerve to the posterior aspect of the leg-the lateral sural cutaneous nerve being entirely absent (fig. 2). In these cases the posterior femoral

Fig. 1 The peroneal communicating nerve as one of the terminals of the lateral sural cutaneous nerve.

Fig. 2 The peroneal communicating nerve arising directly from the common peroneal nerve as its only branch to the posterior aspect of the leg.

Fig. 3 The direct and separate origin of the peroneal communicating nerve.

Fig. 4 The peroneal communicating nerve as the main stem, giving rise to lateral sural cutaneous branches throughout its course.

Fig. 5 A common trunk bifurcating into the peroneal communicating and lateral sural cutaneous nerves. 


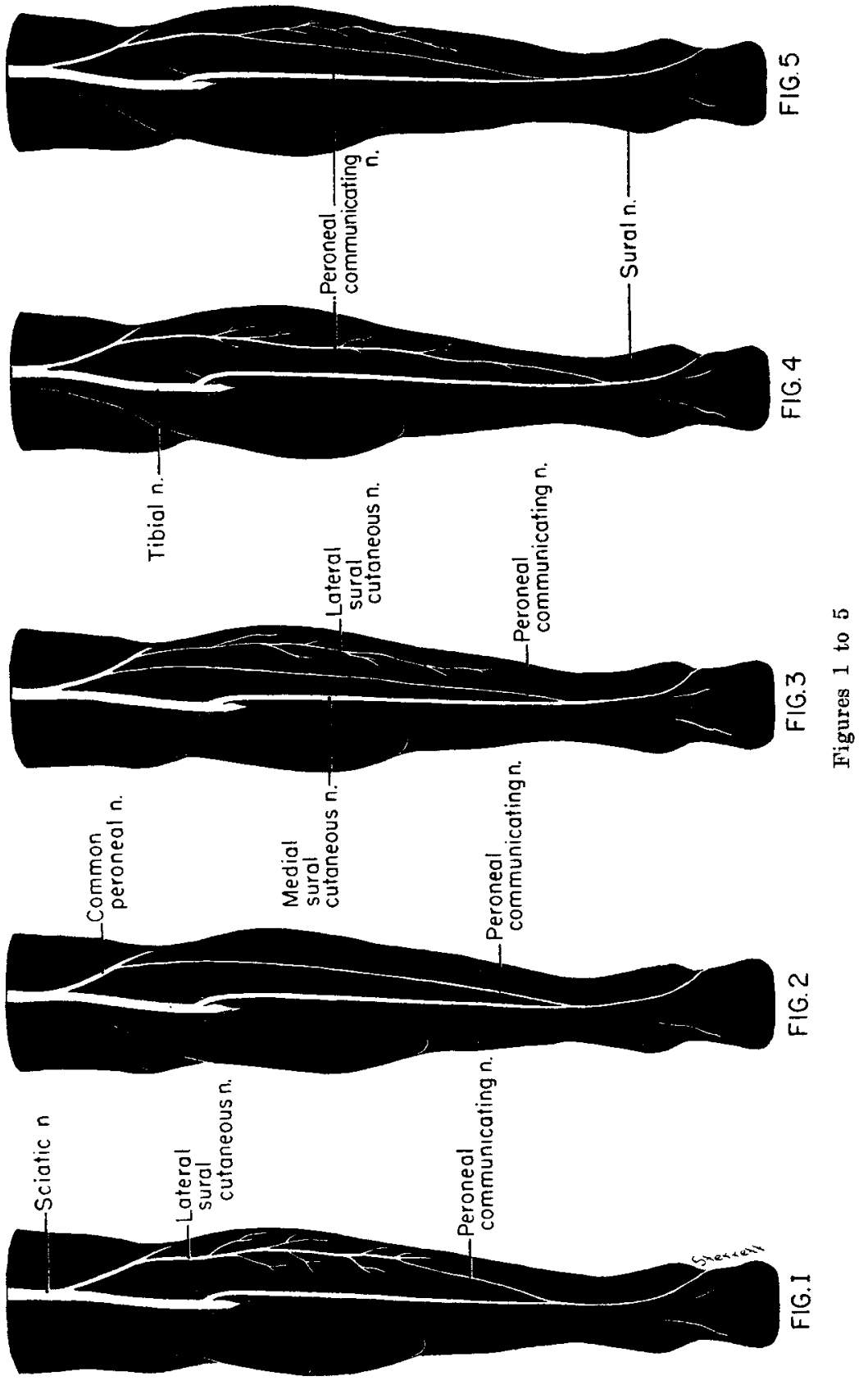


cutaneous nerve and branches of the saphenous nerve supplied much of the cutaneous area of the posterior part of the leg. In $19.5 \%$ it was the first branch of the common peroneal nerve, the lateral sural cutaneous nerve arising distal to it (fig. 3).

Only 58 of the 99 cadavers $(58.6 \%)$ had the same type of origin of the peroneal communicating nerve in both legs.

The sural nerve almost always passed onto the side of the foot as the lateral dorsal cutaneous nerve. However, when no union occurred between the peroneal communicating and the medial sural cutaneous nerves, the medial sural cutaneous nerve usually extended onto the foot as the lateral dorsal cutaneous nerve (fig. 6). This arrangement was observed on 38 of the 198 sides $(19.2 \%)$. In 5 cases the sural nerve or the medial sural cutaneous nerve terminated in calcaneal branches and the main stem of the lateral sural eutaneous nerve continued onto the foot as the lateral dorsal cutaneous nerve (fig's. 7 and 8 ).

No positive correlation was found between the type of origin of the peroneal communicating nerve and the level of union of it with the medial sural cutaneous nerve. No significant differences between the right and left sides, the sex, or the race were found in the peroneal communicating or sural nerves.

\section{DISCUSSION}

Recent investigations on the sural nerve (Williams, '54; Huelke, '57) have shown that it is formed by the union of the medial sural cutaneous nerve and the peroneal communicating nerve in approximately 4 out of 5 cases. The data for this report also indicate that the sural nerve is quite constant $(80.3 \%)$.

Of the 159 sides on which it was found, the peroneal communicating nerve arose from the common peroneal nerve together with the lateral sural cutaneous nerve (58.5\%) or separate from it $(41.5 \%)$. When the peroneal communicating nerve is combined with the lateral sural cutaneous nerve, it arises more often as one of the terminals of the lateral sural 
cutaneous nerve (33.3\%; figs. 1 and 7$)$, rather than from a common stem ( $12 \%$; fig. 5 ), or as the main nerve with lateral sural cutaneous branches arising from it (13.2\% ; fig. 4). This latter type of peroneal communicating nerve which gives rise to small lateral sural cutaneous branches has a direct origin from the common peroneal nerve and therefore representatives of this type can be combined with others which have a direct origin (figs. 2 and 3). Thus, on 87 of the 159 sides $(54.7 \%)$ the peroneal communicating nerve arose directly from the common peroneal nerve.

When the peroneal communicating and medial sural cutaneous nerves do not unite, it is usually the medial sural cutaneous nerve which continues onto the foot as the lateral dorsal cutaneous nerve (fig. 6 ). This arrangement occurred on $19.2 \%$ of sides. In these cases the lateral sural cutaneous nerve supplied the posterior aspect of the leg as far as the ankle. Rarely $(0.5 \%)$, the lateral sural cutaneous nerve passed onto the foot as the lateral dorsal cutaneous nerve (figs. 7 and 8 ). In 4 of these 5 cases, the peroneal communicating nerve arose from the lateral sural cutaneous nerve and joined the medial sural cutaneous nerve to form the sural nerve. However, in these instances the sural nerve terminated in calcaneal branches and did not extend onto the dorsum of the foot. In one instance (fig. 7) there was no connection between the medial and lateral sural cutaneous nerves, but here too the medial sural cutaneous nerve terminated in calcaneal branches, the lateral sural cutaneous nerve passing onto the foot.

The peroneal communicating nerve is absent in all of those cases where no sural nerve is formed (present study - 19.7\%; Huelke, '57-19.3\%). The name peroneal communicating can only be given to that nerve which unites with the medial sural cutaneous nerve to form the sural nerve. At times, in dissection, one sees a nerve which has the course and position of a typical peroneal communicating nerve but it does not unite with the medial sural cutaneous nerve. Rather, it supplies an area of the skin and subcutaneous tissue of the distal, posterior part of the leg. This nerve is purely cutaneous and 
does not communicate and thus, it must be considered as only a cutaneous terminal of the lateral sural cutaneous nerve.

The occurrence of the peroneal communicating nerve is directly related to the frequency of occurrence of the sural nerve. Table 1 presents the data of this and previous investigations on the sural nerve. Here it will be noted that the sural nerve, formed by the union of the peroneal communicating and medial sural cutaneous nerves, varies from $40 \%$ in Kosinski's study to $84 \%$ in the study of Williams. Thus, where either the medial or lateral sural cutaneous nerve con-

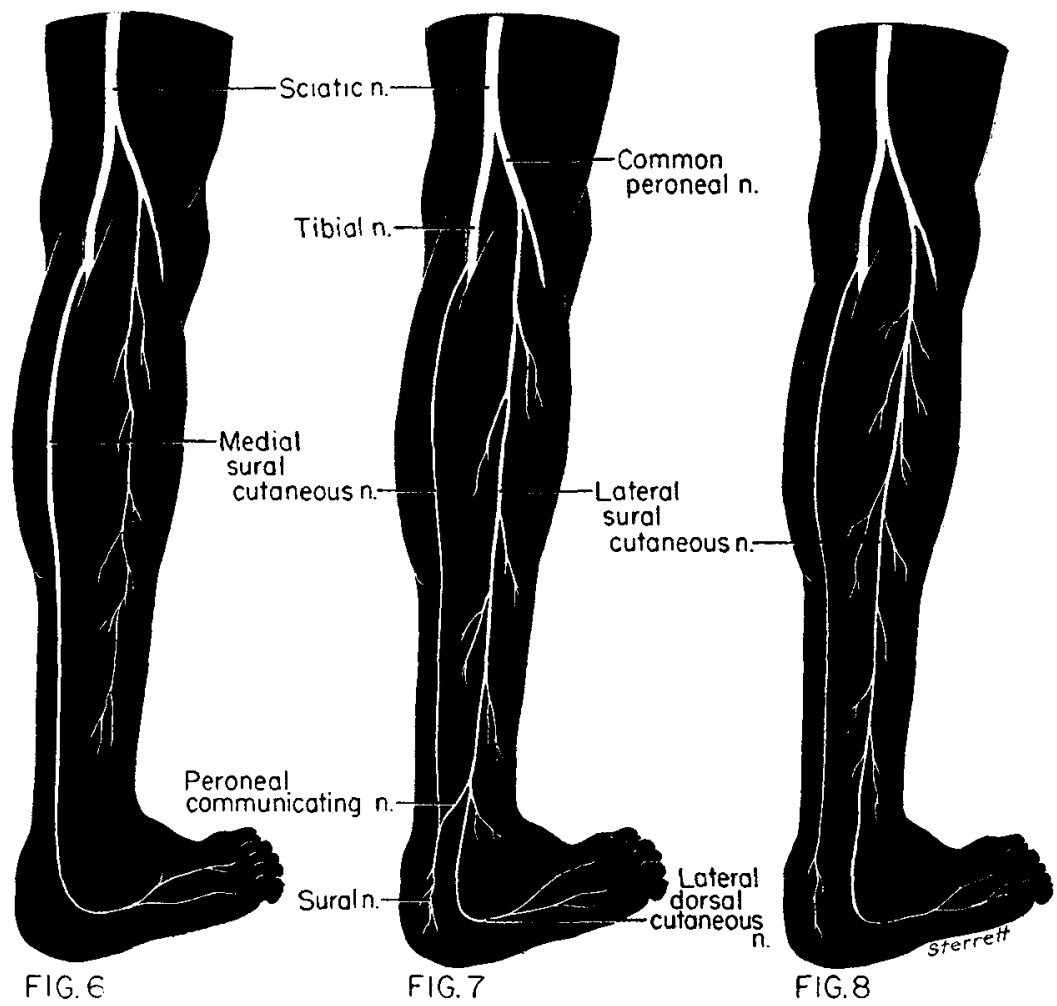

Fig. 6 The medial sural cutaneous nerve passing onto the foot as the lateral dorsal cutaneous nerve.

Fig. 7 The sural nerve terminating in branches to the heel, with the lateral sural cutaneous nerve passing onto the foot.

Fig. 8 The medial sural cutaneous nerve terminating in cutaneous branches to the heel with the Iateral sural cutaneous nerve passing onto the foot. 
tinues directly onto the foot without union, the peroneal communicating nerve is absent. Also it will be noted in table 1 that all authors agree that it is rare for the lateral sural cutaneous nerve to extend onto the foot as the lateral dorsal cutaneous nerve.

TABLE 1

The occurrence of the sural nerve

\begin{tabular}{|c|c|c|c|}
\hline \multirow[b]{2}{*}{ AUTHOR } & \multirow[b]{2}{*}{ PRESENT } & \multicolumn{2}{|c|}{ ABSENT } \\
\hline & & $\begin{array}{l}\text { Med. sural cut. n. } \\
\text { becomes the lat. } \\
\text { dors. cut. n. }\end{array}$ & $\begin{array}{l}\text { Lat. sural cut. } n . \\
\text { becomes the lat. } \\
\text { dors. cut. n. }\end{array}$ \\
\hline $\begin{array}{c}\text { Huelke ('58) } \\
198 \text { limbs }\end{array}$ & $\begin{array}{c}\% \\
80.3\end{array}$ & $\begin{array}{c}\% \\
19.2\end{array}$ & $\begin{array}{l}\% \\
0.5\end{array}$ \\
\hline $\begin{array}{l}\text { Huelke ('57) } \\
352 \text { limbs }\end{array}$ & 80.7 & 19.0 & 0.3 \\
\hline $\begin{array}{l}\text { Williams ('54) } \\
257 \text { limbs }\end{array}$ & 83.7 & 16.0 & 0.4 \\
\hline $\begin{array}{l}\text { P'an ('39) } \\
286 \text { limbs }\end{array}$ & 81.5 & 13.3 & 5.2 \\
\hline $\begin{array}{r}\text { Mogi ('38) } \\
180 \text { limbs }\end{array}$ & 83.3 & 16.7 & $\cdots$ \\
\hline $\begin{array}{l}\text { Ssokolow ('33) } \\
500 \text { limbs }\end{array}$ & 52.6 & 43.8 & 3.6 \\
\hline $\begin{array}{l}\text { Andreassi ('31) } \\
144 \text { limbs }\end{array}$ & 63.9 & 34.7 & 1.4 \\
\hline $\begin{array}{c}\text { Kosinski ('26) } \\
118 \text { limbs }\end{array}$ & 40.2 & 53.8 & 6.0 \\
\hline $\begin{array}{c}\text { Catania ('24) } \\
100 \text { limbs }\end{array}$ & 65.0 & 29.0 & 6.0 \\
\hline $\begin{array}{c}\text { Bardeen ('06) } \\
76 \text { limbs }\end{array}$ & 59.2 & 39.5 & 1.3 \\
\hline
\end{tabular}

Table 2 presents a comparison of the frequency of the various origins of the peroneal communicating nerve based on the total number of sides examined and on the total number of peroneal communicating nerves observed. Kosinski ('26), Bardeen ('06), and Mogi ('38) have indicated that the peroneal communicating nerve is present only in those cases where a sural nerve is formed by the peroneal communicating 


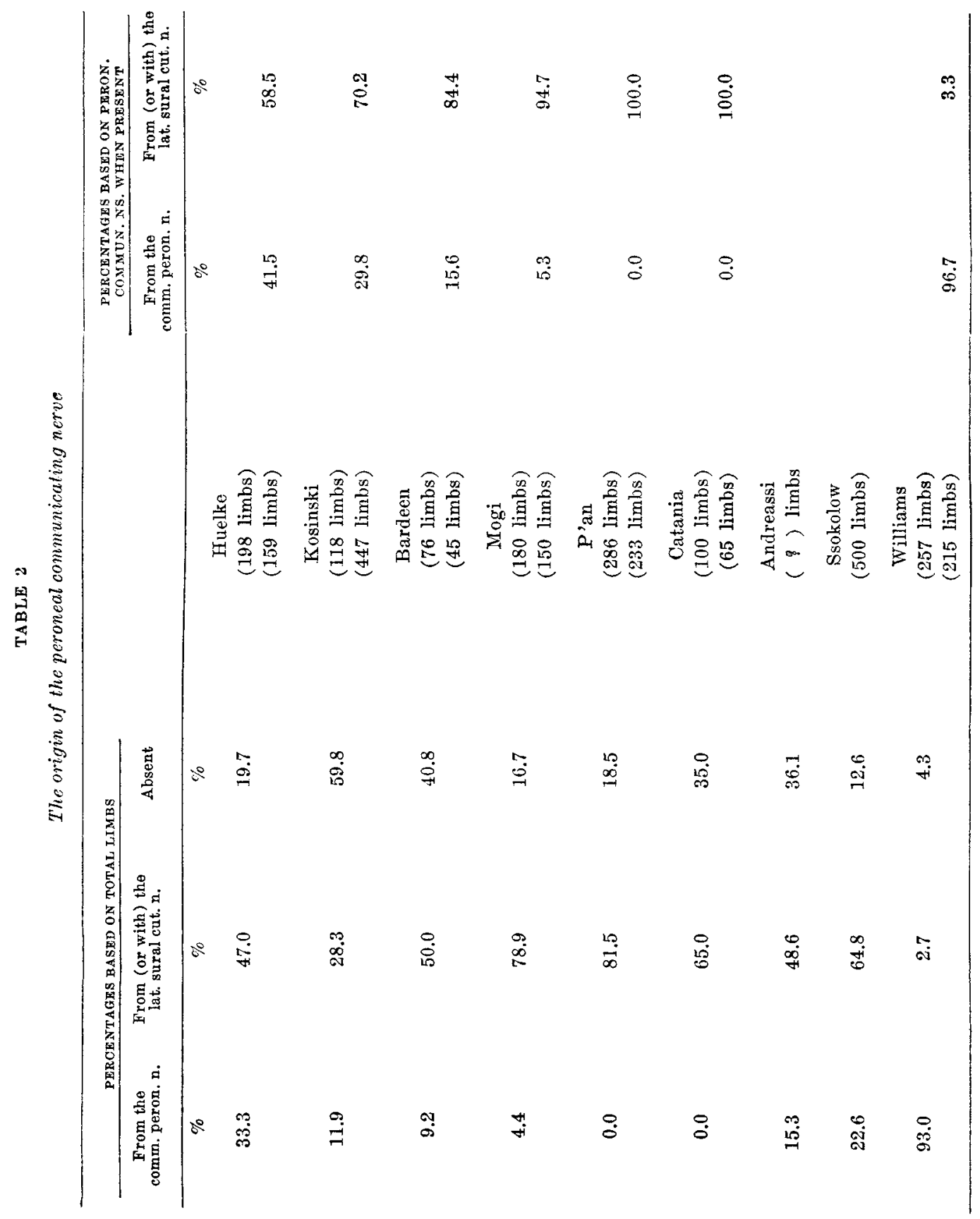


nerve uniting with the medial sural cutaneous nerve. Note that the frequency of each origin of the peroneal communicating nerve, based on the total number of sides examined, varies quite markedly in each of these studies. However, when one considers only the total number of peroneal communicating nerves present in each study, then the difference between their reports are not as great. These three authors agree then, that the peroneal communicating nerve arises more frequently from the lateral sural cutaneous nerve $(70-95 \%)$ than from the common peroneal nerve as a direct and separate branch.

P'an ('39) described the peroneal communicating nerve as arising from the common peroneal nerve, and that it joined the medial sural cutaneous nerve to form the sural nerve in $81.5 \%$ of cases (table 1). Elsewhere in his article he stated that at times the peroneal communicating nerve continues distalward as the sural nerve without joining the medial sural cutaneous nerve. It is known from the present study and from other reports (Kosinski, Bardeen, and Mogi) that it is not the peroneal communicating nerve which continues downward in these cases, but that it is the lateral sural cutaneous nerve. Therefore it is suggested that P'an, when mentioning the origin of this nerve, was referring to the lateral sural cutaneous nerve (and not the peroneal communicating nerve), one branch of which was the peroneal communicating nerve. Thus, in table 2, the origin of the peroneal communicating nerve, according to $\mathrm{P}$ 'an, is presented as arising from the lateral sural cutaneous nerve in all those cases in which it was found $(81.5 \%)$.

The data of Catania ('24) indicate that the peroneal communicating nerve is present in $65 \%$ of cases - all cases in which a sural nerve is formed. In his discussion he claims that all peroneal communicating nerves arise from the lateral sural cutaneous nerve, and so the peroneal communicating nerves of Catania's study are presented in table 2 as arising from the lateral sural cutaneous nerve. The findings of $P$ 'an and Catania on the origin of the peroneal communicating 
nerve, although very high in frequency, agree with those of Kosinski, Bardeen and Mogi.

Andreassi ('54), in his paper on the origin of the peroneal communicating nerve, stated that the nerve arises from the lateral sural cutaneous nerve three times as often as from the common peroneal nerve directly (table 2 ). Because he did not state the number of limbs used in his study, the actual percentages cannot be calculated. In addition he found the peroneal communicating nerve to be present in $63.9 \%$, which agrees exactly with his data of a previous report ('31) presented in table 1. Possibly both reports are based on the same specimens.

Ssokolow ('33) found the peroneal communicating nerve uniting with the medial sural cutaneous nerve in $52.6 \%$ (table 1). Then, by definition, the peroneal communicating nerve is absent in the remaining $47.4 \%$. However, elsewhere in his paper Ssokolow claims that the peroneal communicating nerve is absent in only $12.6 \%$ of sides (see table 2 ). Probably the discrepancy in Ssokolow's data is due to the fact that he considered one of the cutaneous terminals of the lateral sural cutaneous nerve as the peroneal communicating nerve whether or not it joined the medial sural cutaneous nerve. Furthermore he referred to the peroneal communicating nerve as the lateral sural cutaneous nerve, and the lateral sural cutaneous nerve, as used in this and other studies, as the "hinteren Hautnerven." Because of the discrepancy in data and the difference in terminology, Ssokolow's data on the origin of the peroneal communicating nerve cannot be compared with those of other authors.

Williams ('54) is quite clear in his terminology, however his data are also contradictory. These data show that the peroneal communicating nerve joined the medial sural cutaneous nerve in $83.7 \%$ of sides (table 1); elsewhere in his article Williams stated that the peroneal communicating nerve was present in $95.7 \%$. This difference is due to his considering a cutaneous branch (illustrated in his paper as arising directly from the common peroneal nerve) as the peroneal 
communicating nerve although it does not join the medial sural cutaneous nerve. When the frequency of the various origins of the peroneal communicating nerve is calculated on the basis of the total number of peroneal communicating nerves actually present, i.e., the number of sural nerves present which incorporate the peroneal communicating nerve, Williams' data show that it arises directly from the common peroneal nerve in $96.7 \%$. The high frequency of this type of origin of the nerve is completely opposite of the data presented by P'an and Catania, dissimilar to that of Kosinski, Bardeen and Mogi, and occurs more than twice as often as it does in this study (table 2).

Briefly, the data of this report indicate that the peroneal communicating nerve arises with the lateral sural cutaneous nerve in approximately 6 out of 10 limbs. This frequency of origin of the peroneal communicating nerve is much less than that found by all previous investigators, with but one exception (Williams). He presents data which are not only markedly different from this study but also from those of all other authors.

\section{SUMMARY}

The peroneal communicating nerve was studied on 198 adult lower extremities of 92 Caucasian and 7 Negro cadavers.

The union between the peroneal communicating and medial sural cutaneous nerves was seen on 159 sides (80.3\%). This union took place more often in the lower half of the leg $(75 \%)$.

The peroneal communicating nerve arose directly from the common peroneal nerve in $54.7 \%$, usually as a branch entirely separate from the lateral sural cutaneous nerve $(41.5 \%)$. The peroneal communicating nerve gave rise to lateral sural cutaneous branches in $13.2 \%$ of sides.

The peroneal communicating nerve was a terminal branch of the lateral sural cutaneous nerve in one-third of the sides, and arose from a trunk common to it and to the lateral sural cutaneous nerve in $12 \%$. The peroneal communicating nerve was absent in $19.7 \%$ of the 198 sides, and due to its absence, 
no sural nerve was formed in these cases. When this occurs, it is usually the medial sural cutaneous nerve which passed onto the dorsum of the foot as the lateral dorsal cutaneous nerve.

Only $58.6 \%$ of the cadavers had the same type of origin of the peroneal communicating nerve in both leg's. No significant differences between the right and left sides, the sex, or the face were found in the peroneal communicating or sural nerves.

\section{LITER.ATURE CITED}

ANDREASSI, G. 1931 Osservazioni intorno all'origine, comportamento e digtribuzione dei nervi eutaneo mediale della sura, ramo anastomotico peoniero e cutaneo laterale della sura nell'uomo. Ricerche di Morfologia, 11: 83-100.

1954 Observations sur I'origin, le comportement et la distribution $d u$ nerf saphène externe, de l'acessoire du saphene externe et du nerf cutané péronier chez l'Homme. Compt. Rend. Assoc. Anat., 40: $558-564$.

BARDeEn, C. 1906 Development and variation of the nerves and the musculature of the inferior extremity and of the neighboring regions of the trunk in man. Am. J. Anat., 6: 259-391.

Catania, V. 1924 Il comportamento dei nervi eutanei dorsi del piede. Areh. Ital. Anat. Embriol., 21: 295-331.

Cunningham, D. 1951 Text-book of Anatomy. 9th ed. Ed. by J. C. Brash and E. B. Jamieson. Oxford University Press, London.

Grat, H. 1954 Anatomy of the Human Body. 26th ed. Ed. by C. M. Goss. Lea and Febiger, Philadelphia.

Huerke, D. 1957 A study of the formation of the sural nerve in adult man. Am. J. Phys. Anthrop., 15: 137-147.

Kosinskr, C. 1926 The course, mutual relations and distribution of the cutaneous nerves of the metazonal region of the leg and foot. J. Anat. $60: 274-297$.

Mogr, E. 1938 Über die Sensiblen Wandennerven bei den Japanisehen Zwillingen. Okaj. Folia Anat. Jap., 16: 229-274.

Morris, H. 1953 Human Anatomy. 11th ed. Ed. by J. P. Schaeffer, The Blakiston Co., New York.

P'AN, M. 1939 Formation of the sural nerve in the Chinese. Am. J. Phys. Anthrop., 25: 311-321.

Ssokolow, P. 1933 Zur Anatomie des n. suralis beim Menschen und Affen. Ztschr. f. d. ges. Anat., 100: 194-217.

WILliams, D. 1954 A study of the human fibular communicating nerve. Anat. Rec., 120: 533-544. 